\title{
Letter
}

\section{Extant or extinct? White-tailed jack rabbits and Yellowstone's food web}

My recent article in Oryx (Berger, 2008) has provoked a broader debate about food webs and the role of species alleged as missing. In this case, I had suggested that whitetailed jack rabbit Lepus townsendii had disappeared from the two prominent national parks, Grand Teton and Yellowstone, in the Greater Yellowstone Ecosystem of the USA. I want to correct that notion.

Since the article was published I have received at least half a dozen notes from professional biologists and naturalists, including several unmistakable photographs, which demonstrate that these large hares are extant in a relatively small corner of Yellowstone National Park. The National Park Service (Yellowstone) has also received numerous queries about the status of this lagomorph. Although the Service is now able to point out that the species is not locally extinct, further information on the distribution or biology of the hares is unavailable. As a consequence of the media reports and, hence, public attention, the Park is now developing censuses to determine the current distribution of white-tailed jack rabbits.

Given that we now know the white-tailed jack rabbit is extant in Yellowstone National Park, two questions seem pertinent. Firstly, was a presumption of extirpation reasonable? Secondly, do these hares play a functional ecological role? As explained in my original article, I queried knowledgeable Park personnel and examined museum and Park historical records. In prior studies, including one of pronghorn antelope Antilocapra americana (Berger et al., 2006), I had even taken out advertisements in local newspapers, hoping to spark public interest to report when putatively vanishing species had last been seen. In the case of white-tailed jack rabbits, however, a broader sampling of people living adjacent to Yellowstone Park would have improved abilities to detect whether the hares still persist.
As the world's first national park, Yellowstone continues to generate spectacular interest in wildlife, much fuelled by public, media, and scientific attention on only two species: grizzly bears and wolves. However, about 250 formal research projects are permitted in the Park annually, many focused on issues unrelated to mammals. That the whitetailed jack rabbits have never been studied is not so unusual. Restrictions in the availability of funding and the charismatic nature of some species often determine research choices.

That said, the recent media attention on the 'missing' white-tailed jack rabbits has now generated sufficient interest in more than their distribution. Although nothing is known of their ecological role, the potential to find out is opportune, not just in the Park but beyond its borders. In Grand Teton National Park, where there has been little dispute about the functional loss of white-tailed jack rabbits, interest in the potential restoration of this species exists. Studies to understand the population biology, ecology, and community-level dynamics of this under-studied lagomorph are desperately needed not just in Yellowstone park per se but, which was a major point of my article, to further conservation by developing a broader debate about ecological baselines.

\section{JOEL BERGER}

Northern Rockies Field Office, Wildlife Conservation Society and Division of Biological Sciences, University of Montana, Missoula, Montana 59812, USA.

E-mail jberger@wcs.org

\section{References}

Berger, J. (2008) Undetected species losses, food webs, and ecological baselines: a cautionary tale from the Greater Yellowstone Ecosystem, USA. Oryx, 42, 139-142.

Berger, J., CAin, S.L. \& Berger, K. (2006) Connecting the dots: an invariant migration corridor links the Holocene to the present. Biology Letters, 2, 528-531. 